(2) Open Access Full Text Article

\title{
Comparative pharmacokinetics of a fixed-dose combination vs concomitant administration of telmisartan and S-amlodipine in healthy adult volunteers
}

This article was published in the following Dove Press journal:

Drug Design, Development and Therapy

\author{
Minkyung $\mathrm{Oh}^{1,2, *}$ \\ Sung-Eun Park ${ }^{3, *}$ \\ Jong-Lyul Ghim ${ }^{1-3}$ \\ Young-Kyung Choi' \\ Eon-Jeong Shim ${ }^{1-3}$ \\ Jae-Gook Shin ${ }^{1-3}$ \\ Eun-Young Kim ${ }^{1-3}$ \\ 'Department of Pharmacology, \\ ${ }^{2}$ PharmacoGenomics Research Center, \\ Inje University College of Medicine, \\ Busan, ${ }^{3}$ Department of Clinical \\ Pharmacology, Inje University Busan \\ Paik Hospital, Busan, Republic of \\ Korea \\ *These authors contributed equally \\ to this work
}

\begin{abstract}
Objective: This study compared the pharmacokinetic (PK) and safety profiles of a fixed-dose combination (FDC) formulation of telmisartan and S-amlodipine with those of concomitant administration of the two drugs.

Materials and methods: This was an open-label, randomized, crossover study in healthy male Koreans. All subjects were administered an FDC tablet containing $40 \mathrm{mg}$ telmisartan and $5 \mathrm{mg}$ S-amlodipine and were also coadministered the same dose of both drugs given separately. The crossover study design included a 14-day washout period between the two treatments. Blood samples were collected up to $168 \mathrm{~h}$ following drug administration. The plasma concentrations of telmisartan and S-amlodipine were determined by liquid chromatography tandem mass spectrometry. PK parameters and plasma concentration-time curves were compared. Safety was assessed by measuring vital signs, clinical laboratory tests, physical examinations, and patient interviews.
\end{abstract}

Results: The geometric mean ratios and $90 \%$ CIs for the maximum plasma concentration $\left(\mathrm{C}_{\max }\right)$ and area under the curve from time zero to the last sampling time (AUC $)$ were 0.8782 $(0.8167-0.9444)$ and $0.9662(0.9210-1.0136)$ for telmisartan and $1.0069(0.9723-1.0427)$ and 1.0324 (0.9969-1.0690) for S-amlodipine, respectively. A total of 36 adverse events (AEs) were reported by 23 subjects, but no statistical differences were observed between the two treatments. The most frequently reported AE was a mild-to-moderate headache that was generally self-limiting.

Conclusion: For both telmisartan and S-amlodipine, the $\mathrm{C}_{\max }$ and $\mathrm{AUC}_{\mathrm{t}} 90 \% \mathrm{CIs}$ were between $\ln (0.8)$ and $\ln (1.25)$. These results suggest that the FDC formulation is pharmacokinetically bioequivalent and has a similar safety profile to the coadministration of these drugs.

Keywords: bioequivalence, fixed-dose combination, pharmacokinetics, S-amlodipine, telmisartan

\section{Introduction}

Hypertension is a major risk factor for cardiovascular problems, including strokes, myocardial infarction, and heart failure. Additionally, high blood pressure (BP) increases the risk of cardiovascular disease. Therefore, controlling BP is important for preventing cardiovascular disease and reducing the risk of mortality and other complications linked to cardiovascular disease. ${ }^{1,2}$ A systematic review by Mills et al estimated that the global prevalence of hypertension was $31.1 \%$ in $2010 .^{3}$ The Center for Disease Control and Prevention reported a 29.1\% prevalence among US adults between 2001
Correspondence: Eun-Young Kim Department of Clinical Pharmacology, Inje University Busan Paik Hospital, 75 Bokji-ro, Busanjin-Gu, Busan 47392 , Republic of Korea

Tel +825 I 8908972

Fax +82518956438

Email eykim@inje.ac.kr 
and 2012, ${ }^{4}$ and the results from the National Statistical Office in 2015 suggested that the prevalence of hypertension in Korea was $27.9 \% .^{5}$

In general, first-line treatments for hypertension include thiazide-type diuretics, ACE inhibitors, angiotensin receptor blockers (ARBs), and calcium channel blockers (CCBs). If these drugs fail to control BP, a combination of two or more treatments may be used, although combining ACE inhibitors and ARBs is not recommended. ${ }^{6,7}$

Angiotensin II is the principal mediator of the reninangiotensin-aldosterone system and a powerful vasoconstrictor that sustains the elevated levels of BP in hypertensive patients. ${ }^{8,9}$ Angiotensin II ARBs, which antagonize the angiotensin II type I receptor, are widely used as antihypertensive agents because they are effective in lowering BP, can be administered once daily, and are well tolerated. ${ }^{10,11}$ The efficacy of ARBs is comparable with that of ACE inhibitors, and ARBs also reduce the incidence of amlodipine-related edema. ${ }^{8}$ Telmisartan, a high-affinity ARB, lowered BP significantly to a level comparable with the ACE inhibitor lisinopril. Telmisartan caused few adverse events (AEs) in clinical trials and is currently used widely in clinical practice. ${ }^{12,13}$ The absolute bioavailability of telmisartan depends on the dose administered, and its terminal elimination half-life $\left(\mathrm{t}_{1 / 2}\right)$ is $\sim 24 \mathrm{~h} .{ }^{14}$

Amlodipine, a third-generation dihydropyridine CCB, is used to lower BP in hypertensive patients. ${ }^{15-18} \mathrm{~S}$-amlodipine is an enantiomer of amlodipine with good absorption characteristics and bioavailability. ${ }^{15,17-19}$ It is slowly absorbed following administration and is effective over a long period, with a half-life of 36-45 h. ${ }^{19}$ Amlodipine is well tolerated and does not produce some of the undesirable effects associated with other cardiovascular treatments, including changes in serum lipid patterns, disturbances in cardiac conduction, or postural hypotension. ${ }^{20} \mathrm{~S}$-amlodipine lowers BP more effectively than its isomer, R-amlodipine. ${ }^{21,22}$

The primary goal of treating hypertensive patients is to achieve the greatest possible reduction in long-term risk of cardiovascular disease. Most patients require therapy with multiple drugs to reach their target BP and reduce the risk of cardiovascular disease. ${ }^{23,24}$ Monotherapy only achieves the target BP in a minority of patients. A combination of two drugs at low doses is preferable as a first-line treatment when the initial BP is class 2 or 3, the risk of severe cardiovascular events is high or very high, and BP elevation is mild. ${ }^{24} \mathrm{~A}$ single combination pill can simplify the treatment schedule and promote adherence. ${ }^{24}$ The obvious benefits of combination therapy with ARBs and CCBs has led to the development of a fixed-dose combination (FDC) formulation of telmisartan and $\mathrm{S}$-amlodipine for treating hypertension, and a previous study $^{25}$ determined that there was no pharmacokinetic (PK) interaction between these two drugs.

The aim of this study was to compare the PK and safety profiles of an FDC formulation of telmisartan and S-amlodipine with those of coadministration of the two drugs (ClinicalTrials.gov: NCT01340131).

\section{Materials and methods}

The test medication was $40 \mathrm{mg}$ telmisartan $/ 5 \mathrm{mg}$ S-amlodipine FDC tablets (Chong Kun Dang Pharmaceutical Corp., Seoul, Republic of Korea), and the reference tablets were $40 \mathrm{mg}$ of telmisartan (Micardis ${ }^{\circledR}$; Boehringer Ingelheim, Ingelheim, Germany) and $5 \mathrm{mg}$ of S-amlodipine (Anidipine $\mathrm{S}^{\circledR}$; Chong Kun Dang Pharmaceutical Corp.).

\section{Subjects}

Healthy male subjects aged 20-55 years were eligible to participate if their weight was within $20 \%$ of ideal body weight in accordance with Broca's formula. All subjects were considered healthy based on their medical history, physical examinations, 12-lead electrocardiography, and clinical laboratory tests. Subjects with a medical history or diet that might interfere with drug absorption, distribution, metabolism, or excretion were excluded. Subjects were also excluded if any of the following applied: history of allergy or hypersensitivity to telmisartan or amlodipine, history of drug and/or alcohol abuse, systolic blood pressure (SBP) $<90 \mathrm{mmHg}$ and/or diastolic blood pressure (DBP) $<50 \mathrm{mmHg}$, participation in a clinical trial within $90 \mathrm{~d}$ of first administration of the investigational product, donation of blood within $60 \mathrm{~d}$ of first administration of the investigational product; use of medication that would affect drug metabolism within $28 \mathrm{~d}$ of the first administration of the investigational product, or use of any medication that could affect the study results within $10 \mathrm{~d}$ of first administration of the investigational product.

\section{Study design}

This open-label, randomized, crossover design study was performed at the Clinical Trial Center of Inje University Busan Paik Hospital, Busan, Republic of Korea (ClinicalTrials.gov: NCT01340131). The study protocol and informed consent form were approved by the Institutional Review Board of Inje University Busan Paik Hospital, and all subjects provided written informed consent before participating.

We calculated that 28 subjects per treatment would be required to detect a $20 \%$ difference between test and 
reference drugs with $80 \%$ statistical power at a $5 \%$ level of significance, assuming the interindividual variation in the maximum plasma concentration $\left(\mathrm{C}_{\max }\right)$ and the area under the curve from time zero to the last sampling time $\left(\mathrm{AUC}_{\mathrm{t}}\right)$ for telmisartan was $41 \%$. We started the study with 68 subjects, which provided a contingency for patients who might drop out or fail to adhere to both treatments.

All subjects were administered an FDC tablet containing $40 \mathrm{mg}$ telmisartan and $5 \mathrm{mg} \mathrm{S}$-amlodipine and were also coadministered the same dose of both drugs given separately. The crossover study design included a 14-day washout period between the two treatments. Subjects were randomly assigned to one of the two treatment sequences in a 1:1 ratio.

To measure the plasma concentration of telmisartan, blood samples were collected at 0 (pre-dose), 0.25, 0.5, 0.75, $1,1.5,2,4,8,10,12,24,36$, and $48 \mathrm{~h}$ after administration. To measure the plasma concentration of S-amlodipine, blood samples were collected at 0 (pre-dose), 1, 2, 3, 4, 5, 6, 7, 8, $10,12,24,48,72,120$, and $168 \mathrm{~h}$ after administration. A total of 5 or $7 \mathrm{~mL}$ of blood was collected from each subject using a heparinized Vacutainer ${ }^{\circledR}$ tube (Becton Dickinson, Franklin Lakes, NJ, USA). The samples were centrifuged at 3,000 rpm for $10 \mathrm{~min}$ and stored at $-70^{\circ} \mathrm{C}$ for assays.

\section{Safety assessment}

A safety assessment was carried out on all subjects who took at least one study drug. Any AEs were reviewed by integrating data from vital signs, clinical laboratory tests, physical examinations, and patient interviews.

\section{Bioanalysis}

The plasma concentrations of telmisartan and S-amlodipine were analyzed by Seoul Pharma Laboratories (Seoul, Korea) using liquid chromatography tandem mass spectrometric method. Telmisartan and S-amlodipine were quantified using a mass spectrometer in the multiple reaction monitoring mode with positive electrospray ionization. The calibration curves were linear over the ranges of $2-2,000 \mathrm{ng} / \mathrm{mL}$ for telmisartan and $0.05-10 \mathrm{ng} / \mathrm{mL}$ for S-amlodipine in plasma, with coefficients of determination $\left(R^{2}\right)>0.996$ and $>0.997$, respectively. The coefficients of variation (CV) for assay precision were $<6.37 \%$ and $<3.72 \%$, and the accuracies were $>92.99 \%$ and $>88.4 \%$ for telmisartan and S-amlodipine, respectively. No relevant cross-talk or matrix effects were observed.

\section{PK analysis}

The PK parameters of telmisartan and S-amlodipine were assessed by non-compartmental analysis using WinNonlin software (ver 6.1; Pharsight Corp., Mountain View, CA, USA). The $\mathrm{AUC}_{\mathrm{t}}$ was determined using the trapezoidal rule. The area under the plasma concentration-time curve from time zero to infinity $\left(\mathrm{AUC}_{\mathrm{inf}}\right)$ was calculated using the formula: $\mathrm{AUC}_{\mathrm{inf}}=\mathrm{AUC}_{\mathrm{t}}+\mathrm{C}_{\mathrm{t}} / \mathrm{k}$, where $\mathrm{C}_{\mathrm{t}}$ is the last measured plasma concentration and $\mathrm{k}$ is the terminal elimination rate constant. The $\mathrm{C}_{\max }$ and the time to reach $\mathrm{C}_{\max }\left(\mathrm{T}_{\max }\right)$ were determined from the plasma concentration-time curve.

\section{Statistical analysis}

Continuous variable data are expressed as means \pm standard deviations (SDs), and categorical data are expressed as counts or percentages. To assess PK equivalence, $\mathrm{C}_{\max }$ and $\mathrm{AUC}_{\mathrm{t}}$ were log-transformed, and geometric mean ratios (GMRs) and their 90\% CIs were determined. McNemar test was conducted to compare the percentage of AE between treatment groups. Statistical analysis was performed using SAS software (ver 9.4; SAS Institute Inc., Cary, NC, USA).

\section{Results \\ Subjects' characteristics}

Sixty-eight healthy male subjects were enrolled (mean age, $24.1 \pm 1.39$ years; mean weight, $70.16 \pm 8.28 \mathrm{~kg}$; mean height $175.24 \pm 5.68 \mathrm{~cm})$. Eleven subjects did not complete the study: nine withdrew their consent, one withdrew due to administration of concomitant medication, and one due to AEs (Figure 1). Safety profiles were determined using data from 68 subjects who were administered study drugs. PK analysis was performed using data from 57 subjects who completed the study. The baseline characteristics of study subjects are shown in Table 1.

\section{PKs}

The mean plasma concentration-time profiles for the two drugs following administration of $40 \mathrm{mg}$ telmisartan and $5 \mathrm{mg} \mathrm{S}$-amlodipine or the FDC tablet are shown in Figures 2 and 3.

The mean $\mathrm{C}_{\max }$ of telmisartan was $122.13 \pm 64.55 \mathrm{ng} / \mathrm{mL}$ after the FDC tablet and $138.52 \pm 65.45 \mathrm{ng} / \mathrm{mL}$ after concomitant administration. The median (range) $\mathrm{T}_{\max }$ for telmisartan was 2.0 (0.50-4.00) hafter the FDC tablet and $1.5(0.25-4.00) \mathrm{h}$ after concomitant administration. The mean $\mathrm{AUC}_{\mathrm{t}}$ and $\mathrm{AUC}_{\mathrm{inf}}$ for telmisartan were 1,225.73 \pm 749.80 and 1,416.01 $\pm 944.13 \mathrm{ng} \cdot \mathrm{h} / \mathrm{mL}$, respectively, after administration of the FDC tablet and $1,268.76 \pm 740.52$ and $1,448.59 \pm 888.73 \mathrm{ng} \cdot \mathrm{h} / \mathrm{mL}$, respectively, after concomitant administration. The mean $\mathrm{t}_{1 / 2}$ of telmisartan was $17.17 \pm 6.21 \mathrm{~h}$ for the FDC tablet and $17.73 \pm 5.43 \mathrm{~h}$ for coadministration (Table 2 ). 


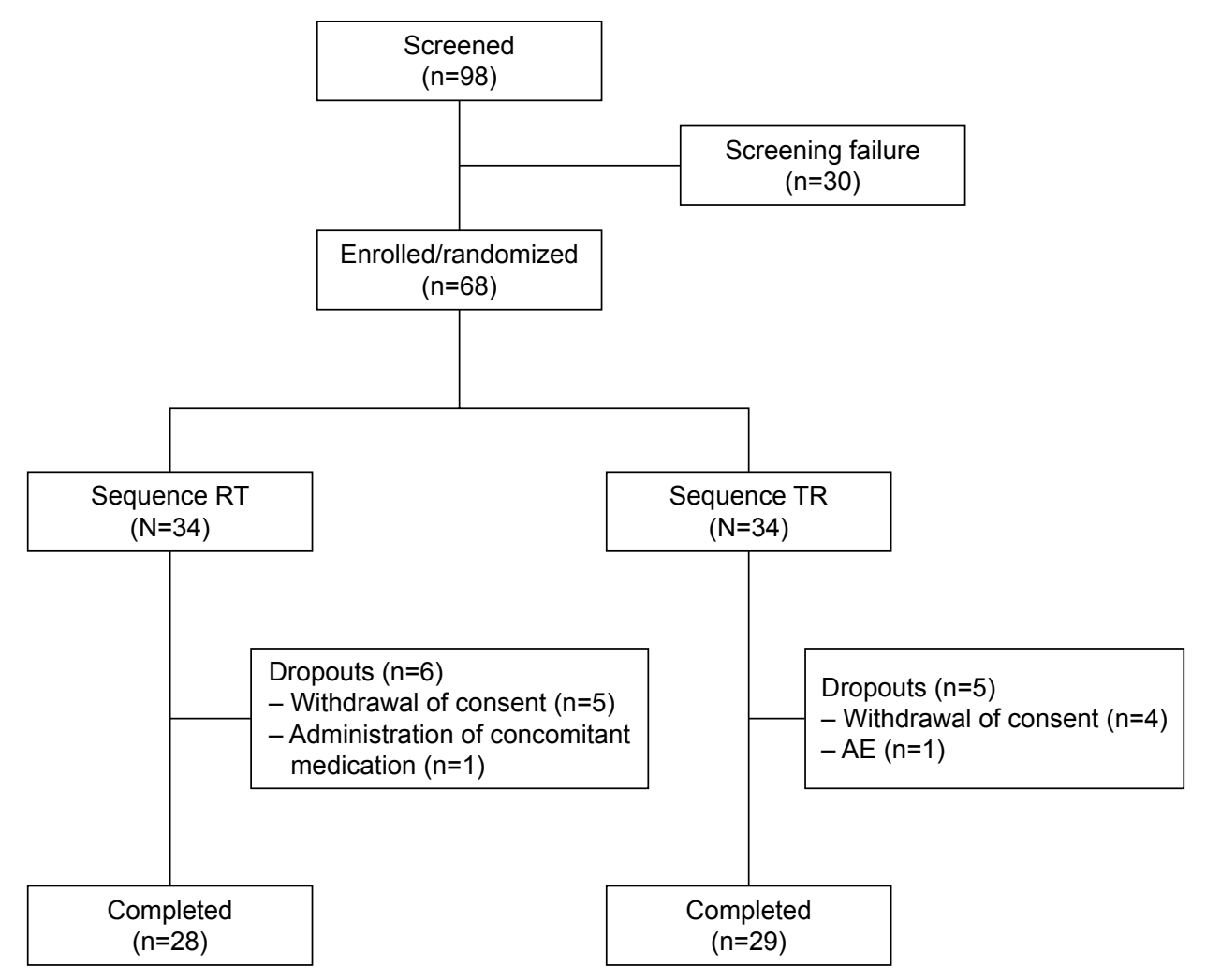

Figure I Disposition of volunteers.

Abbreviations: $A E$, adverse event; $R T$, reference-test; TR, test-reference.

The mean $\mathrm{C}_{\max }$ of S-amlodipine was $2.83 \pm 0.58 \mathrm{ng} / \mathrm{mL}$ after the FDC tablet and $2.83 \pm 0.71 \mathrm{ng} / \mathrm{mL}$ after concomitant administration. The median (range) $\mathrm{T}_{\max }$ for S-amlodipine was $5.00(4.00-10.00) \mathrm{h}$ after the FDC tablet and 5.00 (3.00-8.00) h after concomitant administration. The mean $\mathrm{AUC}_{\mathrm{t}}$ and $\mathrm{AUC}_{\text {inf }}$ for S-amlodipine were $145.57 \pm 37.37$ and $159.08 \pm 46.60 \mathrm{ng} \cdot \mathrm{h} / \mathrm{mL}$, respectively, after administration of the FDC tablet and $141.46 \pm 36.79$ and $154.28 \pm 45.37 \mathrm{ng} \cdot \mathrm{h} / \mathrm{mL}$, respectively, after concomitant administration. The mean $\mathrm{t}_{1 / 2}$ of S-amlodipine was $44.20 \pm 8.62 \mathrm{~h}$ for the FDC tablet and $43.85 \pm 9.67 \mathrm{~h}$ for coadministration (Table 2).

The GMRs (90\% CIs) of $\mathrm{C}_{\max }$ and $\mathrm{AUC}_{\mathrm{t}}$ were 0.8782 (0.8167-0.9444) and 0.9662 (0.9210-1.0136) for telmisartan and $1.0069(0.9723-1.0427)$ and $1.0324(0.9969-1.0690)$ for S-amlodipine, respectively (Table 3 ).

Table I Baseline characteristics of study subjects $(n=68)$

\begin{tabular}{ll}
\hline Variables & Values \\
\hline SBP & $129.59 \pm 7.72(102-138)$ \\
DBP & $81.18 \pm 4.87(70-89)$ \\
Creatinine & $0.94 \pm 0.10(0.74-1.26)$ \\
GOT & $20.4 I \pm 4.52(14-33)$ \\
GPT & $20.7 I \pm 8.90(10-47)$ \\
\hline
\end{tabular}

Note: Data are expressed as mean \pm standard deviation (min-max).

Abbreviations: SBP, systolic blood pressure; DBP, diastolic blood pressure; GOT, glutamin oxalacetic transaminase; GPT, glutamic pyruvate transaminase.

\section{Safety}

During the study, a total of 36 AEs were reported by 23 subjects. The number of subjects reporting AEs following the FDC tablet $(n=17)$ and coadministration $(n=19)$ was similar. The most frequently reported $\mathrm{AE}$ was a mild-to-moderate headache that was generally self-limiting. There were no statistically significant differences between the FDC tablet and coadministration treatments (McNemar test, $p=0.9268$ ).

Headaches were more frequent after coadministration of telmisartan and S-amlodipine $(\mathrm{n}=11)$ than following the FDC tablet $(\mathrm{n}=8)$. Drug-related AEs (FDC tablet vs coadministration) included headaches ( $\mathrm{n}=7$ vs 9 ), dizziness ( $n=1$ vs 1 ), increased levels of AST ( $n=0$ vs 1 ), increased levels of ALT ( $n=0$ vs 1 ), increased levels of creatinine in the blood ( $\mathrm{n}=1$ vs 0 ), and hypotension ( $\mathrm{n}=1$ vs 0 ). The baseline level of serum creatinine of one subject in the FDC group was 0.91 , increased to 1.57 , and normalized to baseline level. The baseline values of SBP and DBP of one subject in the FDC group were 113 and 74, respectively, decreased to 86 and 45, and normalized to baseline level. Two events necessitated intervention: one case of severe headache required administration of acetaminophen, and one case of mild hypotension required BP monitoring. The other AEs were mild and resolved spontaneously; there were no serious AEs. 

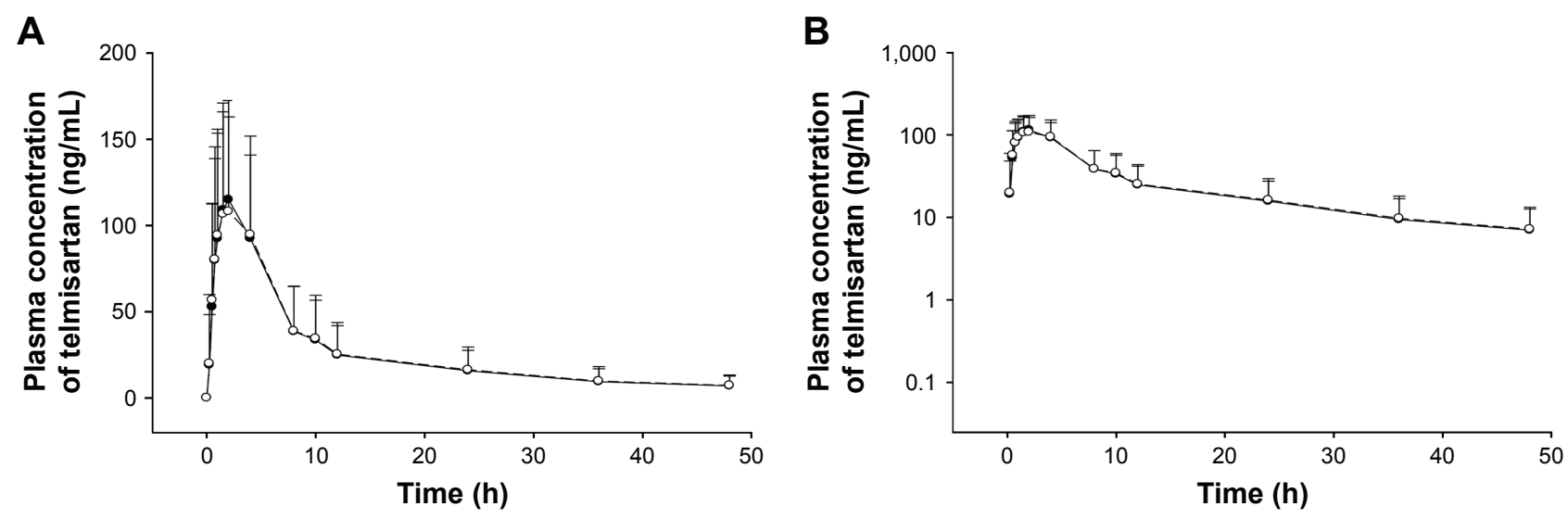

- Coadministration of $40 \mathrm{mg}$ telmisartan $/ 5 \mathrm{mg}$ S-amlodipine

-o- FDC tablet (40 mg telmisartan/5 mg S-amlodipine)

Figure 2 Mean (standard deviation) plasma concentration profiles of telmisartan after administration of FDC tablet ( $40 \mathrm{mg}$ telmisartan $/ 5 \mathrm{mg}$ S-amlodipine) and coadministration of $40 \mathrm{mg}$ telmisartan with $5 \mathrm{mg} \mathrm{S}$-amlodipine in healthy male subjects.

Notes: Linear scale (A); log scale (B).

Abbreviation: FDC, fixed-dose combination.

No clinically significant changes were observed in the vital signs, laboratory test results, during the physical examinations, or on the electrocardiograms.

After administration of FDC tablet and coadministration, the maximum decreases in mean SDP and DBP were $115.42 \pm 10.63$ and $63.53 \pm 7.34$, respectively (Figure 4).

\section{Discussion}

This study evaluated the PKs and safety profiles of an FDC formulation containing $40 \mathrm{mg}$ telmisartan and $5 \mathrm{mg}$ S-amlodipine, together with coadministration of the same doses of both drugs given separately. The $90 \%$ CIs for GMRs of the $\mathrm{PK}$ parameters $\mathrm{C}_{\max }$ and $\mathrm{AUC}_{\mathrm{t}}$ were within the acceptable limits of bioequivalence $(0.8-1.25)$, indicating that the FDC formulation was bioequivalent to coadministration. Additionally, no statistically significant clinical differences were observed among the AEs that followed administration of the two formulations.

The 8th report of the Joint National Committee and guidelines from the European Society of Hypertension (ESH) and the European Society of Cardiology (ESC) 2013 recommend that antihypertensive therapy should be provided to patients with grade 1 hypertension who have target organ damage, cardiovascular risk factors, or no reduction in BP despite lifestyle changes. Combination therapy is recommended if the target BP is not reached after 1 month of monotherapy. The ESH and ESC 2013 guidelines also explain that monotherapy successfully lowers BP in only a
A

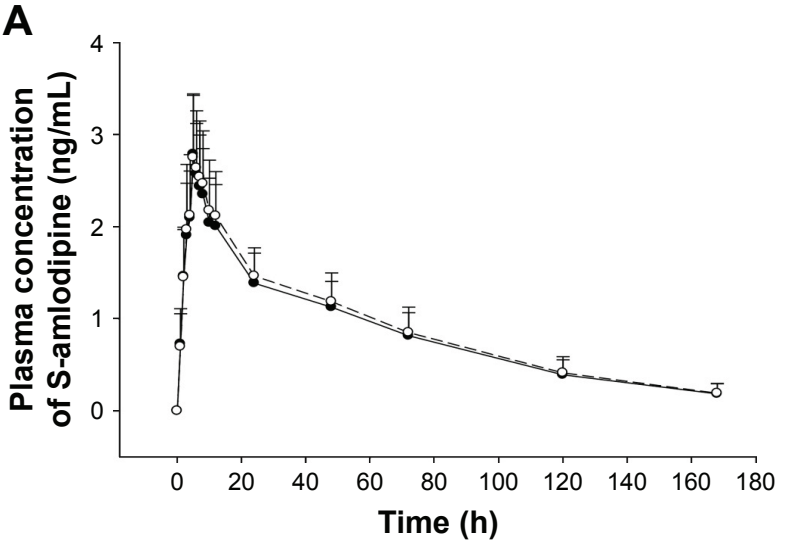

B

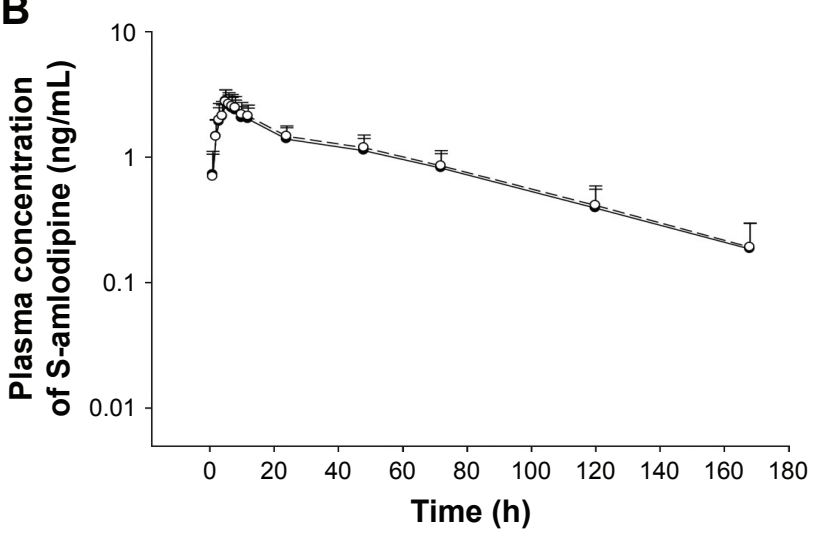

- Coadministration of $40 \mathrm{mg}$ telmisartan $/ 5 \mathrm{mg} \mathrm{S}$-amlodipine

- o- FDC tablet (40 mg telmisartan/5 mg S-amlodipine)

Figure 3 Mean (standard deviation) plasma concentration profile of S-amlodipine after administration of FDC tablet ( $40 \mathrm{mg}$ telmisartan/5 mg S-amlodipine) and coadministration of $40 \mathrm{mg}$ telmisartan with $5 \mathrm{mg} \mathrm{S}$-amlodipine in healthy male subjects.

Notes: Linear scale (A); log scale (B).

Abbreviation: FDC, fixed-dose combination. 
Table 2 PK properties of telmisartan and S-amlodipine following administration of an FDC tablet containing 40 mg telmisartan and $5 \mathrm{mg}$ S-amlodipine or coadministration of $40 \mathrm{mg}$ telmisartan with $5 \mathrm{mg}$ S-amlodipine in healthy male subjects $(\mathrm{n}=57)$

\begin{tabular}{llll}
\hline Ingredient & PK parameter & FDC & Coadministration \\
\hline Telmisartan & $\mathrm{C}_{\max }(\mathrm{ng} / \mathrm{mL})$ & $122.13 \pm 64.55$ & $138.52 \pm 65.45$ \\
& $\mathrm{AUC}(\mathrm{ng} \cdot \mathrm{h} / \mathrm{mL})$ & $1,225.73 \pm 749.80$ & $1,268.76 \pm 740.52$ \\
& $\mathrm{AUC}_{\text {inf }}(\mathrm{ng} \cdot \mathrm{h} / \mathrm{mL})$ & $1,416.01 \pm 944.13$ & $1,448.59 \pm 888.73$ \\
& $\mathrm{t}_{1 / 2}(\mathrm{~h})$ & $17.17 \pm 6.21$ & $17.73 \pm 5.43$ \\
S-amlodipine & $\mathrm{T}_{\max }(\mathrm{h})^{\mathrm{a}}$ & $2.0(0.50 \sim 4.00)$ & $1.5(0.25 \sim 4.00)$ \\
& $\mathrm{C}_{\max }(\mathrm{ng} / \mathrm{mL})$ & $2.83 \pm 0.58$ & $2.83 \pm 0.71$ \\
& $\mathrm{AUC}(\mathrm{ng} \cdot \mathrm{h} / \mathrm{mL})$ & $145.57 \pm 37.37$ & $141.46 \pm 36.79$ \\
& $\mathrm{AUC}_{\text {inf }}(\mathrm{ng} \cdot \mathrm{h} / \mathrm{mL})$ & $159.08 \pm 46.60$ & $154.28 \pm 45.37$ \\
& $\mathrm{t}_{1 / 2}(\mathrm{~h})$ & $44.20 \pm 8.62$ & $43.85 \pm 9.67$ \\
& $\mathrm{~T}_{\max }(\mathrm{h})^{\mathrm{a}}$ & $5.00(4.00 \sim 10.00)$ & $5.00(3.00 \sim 8.00)$ \\
\hline
\end{tabular}

Notes: Data are expressed as mean \pm standard deviation; avalues expressed as median (range).

Abbreviations: PK, pharmacokinetic; FDC, fixed-dose combination; $C_{\max }$, maximum plasma concentration; $T_{\max }$, time to reach $C_{\max }$; $A U C_{\text {inf }}$ area under the plasma concentration-time curve from time zero to infinity; $A \cup C_{t^{\prime}}$, area under the curve from time zero to the last sampling time; $t_{1 / 2}$, terminal elimination half-life.

minority of hypertensive patients and that most require two or more concomitant therapies. ${ }^{24,26,27}$ Recent clinical trials have reported that combining ARBs and CCBs to lower BP can also reduce the level of cardiovascular risk. ${ }^{28}$

$\mathrm{S}$-amlodipine is the most effective calcium-channelblocking form of amlodipine. ${ }^{22}$ The $\mathrm{R}$-amlodipine isomer is $\sim 1,000$-fold less potent as a CCB. ${ }^{29}$ Therefore, the antihypertensive and anti-anginal effects of amlodipine are attributed to $\mathrm{S}$-amlodipine, whereas $\mathrm{R}$-amlodipine is considered an inactive or counterproductive impurity. ${ }^{30}$ Therefore, in this study, we used S-amlodipine as our CCB. When this study was planned, we had no information on the intra-individual variation of the primary $\mathrm{PK}$ parameters $\mathrm{C}_{\max }$ and $\mathrm{AUC}_{\mathrm{t}}$. We assumed that the intra-individual variation would be lower than the interindividual variation and calculated our sample size using the intra-individual variation information from other studies. The intra-individual $\mathrm{CVS}_{\mathrm{s}}$ in $\mathrm{C}_{\max }$ and $\mathrm{AUC}_{\mathrm{t}}$ for telmisartan was $23.17 \%$ and $15.28 \%$, respectively. The intraindividual CVs in $\mathrm{C}_{\max }$ and $\mathrm{AUC}_{\mathrm{t}}$ for $\mathrm{S}$-amlodipine was lower at $11.16 \%$ and $11.14 \%$, respectively. Therefore, there were enough study subjects to compare the PK profiles of the FDC and coadministration of telmisartan and S-amlodipine.
Generally, telmisartan is absorbed rapidly and its maximum concentration occurs at $1 \mathrm{~h}$ (range: 0.5-2.0 h). It has a long $\mathrm{t}_{1 / 2}$ (range: $20-24 \mathrm{~h}$ ) and nonlinear PK properties. ${ }^{31}$ Telmisartan plasma concentrations also vary significantly among individuals, probably because of genetic variations in metabolic enzymes and transporters, including UGT1A3 and SLCO1B3. ${ }^{32,33}$ The PK parameters of S-amlodipine for the FDC tablet and coadministration were similar. These results resemble those reported by Park et al. ${ }^{16,18}$

This study had several limitations. It used a single dose and included only healthy male participants in the fasted state. Because these conditions are not representative of the general hypertensive patient population, a further longterm study of hypertensive patients is warranted. Also, because all participants were Asian (Korean) males, another study is needed in order to generalize this result to other populations.

\section{Conclusion}

This study demonstrates that the PK profile of an FDC formulation of telmisartan and S-amlodipine was bioequivalent to the coadministration of these drugs. The corresponding

Table 3 Geometric mean ratios $(90 \% \mathrm{Cl})$ of the PK properties of telmisartan and S-amlodipine following administration of an FDC tablet containing $40 \mathrm{mg}$ telmisartan and $5 \mathrm{mg}$ S-amlodipine or coadministration of $40 \mathrm{mg}$ telmisartan with 5 mg S-amlodipine in healthy male subjects $(n=57)$

\begin{tabular}{llll}
\hline Ingredient & PK parameter & $\begin{array}{l}\text { Geometric mean } \\
\text { ratio (90\% Cl) }\end{array}$ & $\begin{array}{l}\text { Intra-individual } \\
\text { CV (\%) }\end{array}$ \\
\hline Telmisartan & $\mathrm{C}_{\max }(\mathrm{ng} / \mathrm{mL})$ & $0.8782(0.8167-0.9444)$ & 23.17 \\
& $\mathrm{AUC}_{\mathrm{t}}(\mathrm{ng} \cdot \mathrm{h} / \mathrm{mL})$ & $0.9662(0.9210-1.0136)$ & 15.28 \\
S-amlodipine & $\mathrm{C}_{\max }(\mathrm{ng} / \mathrm{mL})$ & $1.0069(0.9723-1.0427)$ & 11.16 \\
& $\mathrm{AUC}(\mathrm{ng} \cdot \mathrm{h} / \mathrm{mL})$ & $1.0324(0.9969-1.0690)$ & 11.14 \\
\hline
\end{tabular}

Abbreviations: PK, pharmacokinetic; FDC, fixed-dose combination; $\mathrm{CV}$, coefficient of variation; $\mathrm{C}_{\max }$, maximum plasma concentration; $A \mathrm{C}_{\mathrm{t}}$, area under the curve from time zero to the last sampling time. 

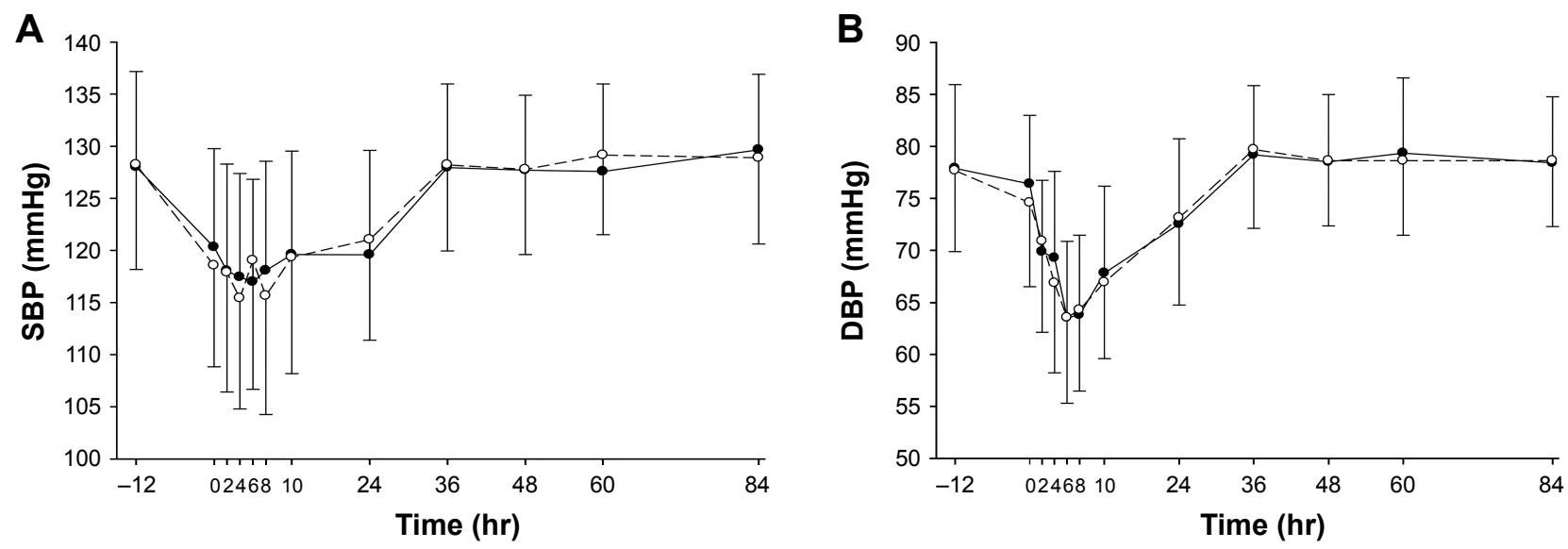

- C Coadministration of telmisartan $40 \mathrm{mg} / \mathrm{S}$-amlodipine $5 \mathrm{mg} \quad$ - . - FDC tablet (telmisartan/S-amlodipine $40 \mathrm{mg} / 5 \mathrm{mg}$ )

Figure 4 Mean (standard deviation) SBP and DBP after administration of FDC tablet (40 mg telmisartan/5 mg S-amlodipine) and coadministration of 40 mg telmisartan with $5 \mathrm{mg}$ S-amlodipine in healthy male subjects.

Notes: SBP (A); DBP (B).

Abbreviations: SBP, systolic blood pressure; DBP, diastolic blood pressure; FDC, fixed-dose combination.

safety profiles were also similar, and both formulations of telmisartan and S-amlodipine were well tolerated.

\section{Acknowledgments}

The funding for this study was provided by Chong Kun Dang Pharmaceutical Corp. (Seoul, Republic of Korea), and we thank Ji-Hong Shon of the US the Food and Drug Administration for his support in this clinical trial.

\section{Disclosure}

The authors report no conflicts of interest in this work.

\section{References}

1. Kearney PM, Whelton M, Reynolds K, Muntner P, Whelton PK, He J. Global burden of hypertension: analysis of worldwide data. Lancet. 2005;365(9455):217-223.

2. Lewington S, Clarke R, Qizilbash N, Peto R, Collins R; Prospective Studies Collaboration. Age-specific relevance of usual blood pressure to vascular mortality: a meta-analysis of individual data for one million adults in 61 prospective studies. Lancet. 2002;360(9349): 1903-1913.

3. Mills KT, Bundy JD, Kelly TN, et al. Global disparities of hypertension prevalence and control: a systematic analysis of population-based studies from 90 countries. Circulation. 2016;134(6):441-450.

4. cdc.gov [homepage on the Internet]. Hypertension Among Adults in the United States: National Health and Nutrition Examination Survey, 2011-2012. Centers for Disease Control and Prevention; 2013. Available from: https://www.cdc.gov/nchs/products/databriefs/db133.htm. Accessed November 3, 2017.

5. 100 indicators of Korean Statistical Information Service. 2015. Available from https://kosis.kr/nsportalStats/nsportalStats_0102Body. jsp;jsessionid=uMBw1 xbPFOdNUBjXEBfDU7n9aGSkYXI3m 1 htNKgA10AN7qUsg01JGgobaQp8OyA9.STAT_WAS1_servlet_ engine1?menuId=11\&NUM=1075. Accessed November 28, 2017.

6. Kim HS, Chang K, Koh YS, et al. CYP2C19 poor metabolizer is associated with clinical outcome of clopidogrel therapy in acute myocardial infarction but not stable angina. Circ Cardiovasc Genet. 2013;6(5):514-521.
7. Kim HS, Kim GY, Yeo CW, et al. The effect of Ginkgo biloba extracts on the pharmacokinetics and pharmacodynamics of cilostazol and its active metabolites in healthy Korean subjects. Br J Clin Pharmacol. 2014;77(5):821-830.

8. Kjeldsen SE, Julius S. Hypertension mega-trials with cardiovascular end points: effect of angiotensin-converting enzyme inhibitors and angiotensin receptor blockers. Am Heart J. 2004;148(5):747-754.

9. Rosario BH, Hendra TJ. Telmisartan in the treatment of hypertension. Expert Opin Drug Metab Toxicol. 2008;4(4):485-492.

10. Benndorf RA, Boger RH. Pleiotropic effects of telmisartan: still more to come? J Hypertens. 2008;26(5):854-856.

11. Burnier M, Brunner HR. Angiotensin II receptor antagonists. Lancet. 2000;355(9204):637-645.

12. Neutel JM, Frishman WH, Oparil S, Papademitriou V, Guthrie G. Comparison of telmisartan with lisinopril in patients with mild-to-moderate hypertension. Am J Ther. 1999;6(3):161-166.

13. Karlberg BE, Lins LE, Hermansson K. Efficacy and safety of telmisartan, a selective AT1 receptor antagonist, compared with enalapril in elderly patients with primary hypertension. TEES Study Group. J Hypertens. 1999;17(2):293-302.

14. Benson SC, Pershadsingh HA, Ho CI, et al. Identification of telmisartan as a unique angiotensin II receptor antagonist with selective PPARgammamodulating activity. Hypertension. 2004;43(5):993-1002.

15. Abernethy DR. The pharmacokinetic profile of amlodipine. Am Heart J. 1989;118(5 Pt 2):1100-1103.

16. Carvalho M, Oliveira CH, Mendes GD, Sucupira M, Moraes ME, De Nucci G. Amlodipine bioequivalence study: quantification by liquid chromatography coupled to tandem mass spectrometry. Biopharm Drug Dispos. 2001;22(9):383-390.

17. Liu Y, Jia J, Liu G, Li S, Lu C, Yu C. Pharmacokinetics and bioequivalence evaluation of two formulations of 10-mg amlodipine besylate: an open-label, single-dose, randomized, two-way crossover study in healthy Chinese male volunteers. Clin Ther. 2009;31(4):777-783.

18. Park JY, Kim KA, Park PW, et al. Pharmacokinetic and pharmacodynamic characteristics of a new S-amlodipine formulation in healthy Korean male subjects: a randomized, open-label, two-period, comparative, crossover study. Clin Ther. 2006;28(11):1837-1847.

19. Meredith PA, Elliott HL. Clinical pharmacokinetics of amlodipine. Clin Pharmacokinet. 1992;22(1):22-31.

20. Murdoch D, Heel RC. Amlodipine. A review of its pharmacodynamic and pharmacokinetic properties, and therapeutic use in cardiovascular disease. Drugs. 1991;41(3):478-505. 
21. Luksa J, Josic D, Podobnik B, Furlan B, Kremser M. Semipreparative chromatographic purification of the enantiomers S-(-)amlodipine and R-(+)-amlodipine. J Chromatogr B Biomed Sci Appl. 1997;693(2):367-375.

22. Goldmann S, Stoltefuss J, Born L. Determination of the absolute configuration of the active amlodipine enantiomer as (-)-S: a correction. J Med Chem. 1992;35(18):3341-3344.

23. Littlejohn TW 3rd, Majul CR, Olvera R, et al. Results of treatment with telmisartan-amlodipine in hypertensive patients. J Clin Hypertens (Greenwich). 2009;11(4):207-213.

24. Mancia G, De Backer G, Dominiczak A, et al. 2007 ESH-ESC Practice Guidelines for the Management of Arterial Hypertension: ESH-ESC Task Force on the Management of Arterial Hypertension. J Hypertens. 2007;25(9):1751-1762.

25. Noh YH, Lim HS, Kim MJ, et al. Pharmacokinetic interaction of telmisartan with s-amlodipine: an open-label, two-period crossover study in healthy Korean male volunteers. Clin Ther. 2012;34(7): $1625-1635$

26. James PA, Oparil S, Carter BL, et al. 2014 evidence-based guideline for the management of high blood pressure in adults: report from the panel members appointed to the Eighth Joint National Committee (JNC 8). JAMA. 2014;311(5):507-520.

27. Mancia G, Fagard R, Narkiewicz K, et al. 2013 ESH/ESC Guidelines for the management of arterial hypertension: the Task Force for the management of arterial hypertension of the European Society of Hypertension (ESH) and of the European Society of Cardiology (ESC). J Hypertens. 2013;31(7):1281-1357.
28. da Silva PM. Efficacy of fixed-dose combination therapy in the treatment of patients with hypertension: focus on amlodipine/valsartan. Clin Drug Investig. 2010;30(9):625-641.

29. Zhang XP, Loke KE, Mital S, Chahwala S, Hintze TH. Paradoxical release of nitric oxide by an L-type calcium channel antagonist, the R+ enantiomer of amlodipine. J Cardiovasc Pharmacol. 2002; 39(2):208-214.

30. Rentsch KM. The importance of stereoselective determination of drugs in the clinical laboratory. J Biochem Biophys Methods. 2002; 54(1-3):1-9.

31. Deppe S, Boger RH, Weiss J, Benndorf RA. Telmisartan: a review of its pharmacodynamic and pharmacokinetic properties. Expert Opin Drug Metab Toxicol. 2010;6(7):863-871.

32. Yamada A, Maeda K, Ishiguro N, et al. The impact of pharmacogenetics of metabolic enzymes and transporters on the pharmacokinetics of telmisartan in healthy volunteers. Pharmacogenet Genomics. 2011; 21(9):523-530.

33. Ieiri I, Nishimura $\mathrm{C}$, Maeda $\mathrm{K}$, et al. Pharmacokinetic and pharmacogenomic profiles of telmisartan after the oral microdose and therapeutic dose. Pharmacogenet Genomics. 2011;21(8):495-505.
Drug Design, Development and Therapy

\section{Publish your work in this journal}

Drug Design, Development and Therapy is an international, peerreviewed open-access journal that spans the spectrum of drug design and development through to clinical applications. Clinical outcomes, patient safety, and programs for the development and effective, safe, and sustained use of medicines are the features of the journal, which

\section{Dovepress}

has also been accepted for indexing on PubMed Central. The manuscript management system is completely online and includes a very quick and fair peer-review system, which is all easy to use. Visit http://www.dovepress.com/testimonials.php to read real quotes from published authors. 